\title{
Wildfire Policy Challenge in the United States: Implications for Wildfire Risk Reduction in Missouri
}

\author{
Omolola Akinola $^{1} \&$ Jimmy Adegoke $^{1}$ \\ ${ }^{1}$ Department of Geosciences, University of Missouri Kansas City, USA \\ Correspondence: Omolola Akinola, Department of Geosciences, University of Missouri Kansas City, MO 64110, \\ USA.E-mail: ovagh9@mail.umkc.edu
}

Received: November 22, 2019

doi:10.5539/jsd.v13n3p144
Accepted: April 20, $2020 \quad$ Online Published: May 31, 2020

URL: https://doi.org/10.5539/jsd.v13n3p144

\begin{abstract}
The study examines the crisis of wildfire destruction in the United States and the various wildfire policies in place to mitigate the risk of wildfire. It also considers the factors affecting the incidence of wildfire in Missouri and finally it analyses the reasons for wildfire policy failure in the United States and suggestion on how to approach the challenge. The study concludes by examining the implication of social and demographic characteristics of forest landowners, land use change, wildland urban interface and climate change on wildfire risk reduction in Missouri.
\end{abstract}

Keywords: wildfire policy, risk reduction, wildland-urban interface (WUI), land use change, Missouri

\section{Introduction}

The policy challenge caused by wildfires is a major source of concern in the United States (Busenberg, 2004). The destructive effects of wildfire in the United States have led to loss of lives, damage to property, and loss to ecosystem, tourism, timber and even air quality (General Accounting Office (GAO), 1999a, 1999b, 2000; US Department of Agriculture (USDA) Forest Service and US Department of the Interior [DOI], 2000; USDA Forest Service, 2000. The cost of firefighting is also on the rise. It was estimated that over $\$ 2$ billion were incurred to firefighting in 2000 alone. In Missouri, wildfire is still a major challenge because of the destruction to property and ecosystem. Fig. 1 shows the average acres burned from 1940s through 2008. Fig. 2 shows wildfires and total average burned, and Fig. 3 shows wildfire per year by size. In order to reduce or mitigate this trend, the United States put in place several wildfire policy frameworks. The objective of this paper is to examine some of the wildfire policy in the United States; analyze the current challenges facing their implementation, consider the implication of these for wildfire risk reduction in Missouri.

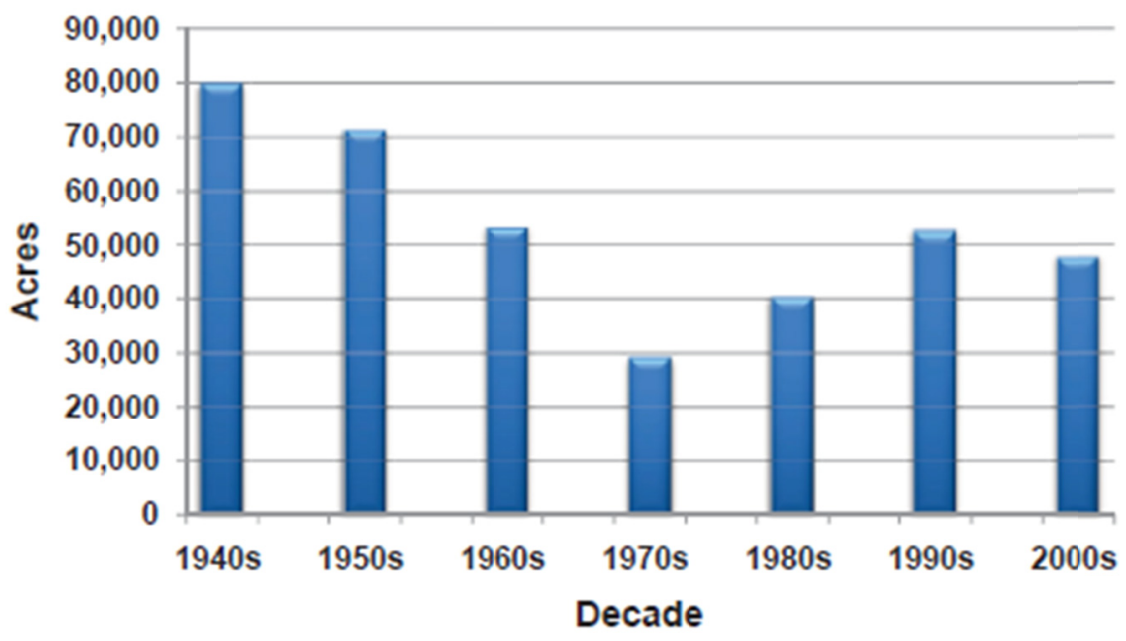

Figure 1. Average acres burned per year by wildfire in Missouri (1940-2008)

Source / Data from Missouri Department of Conservation (MDC) 


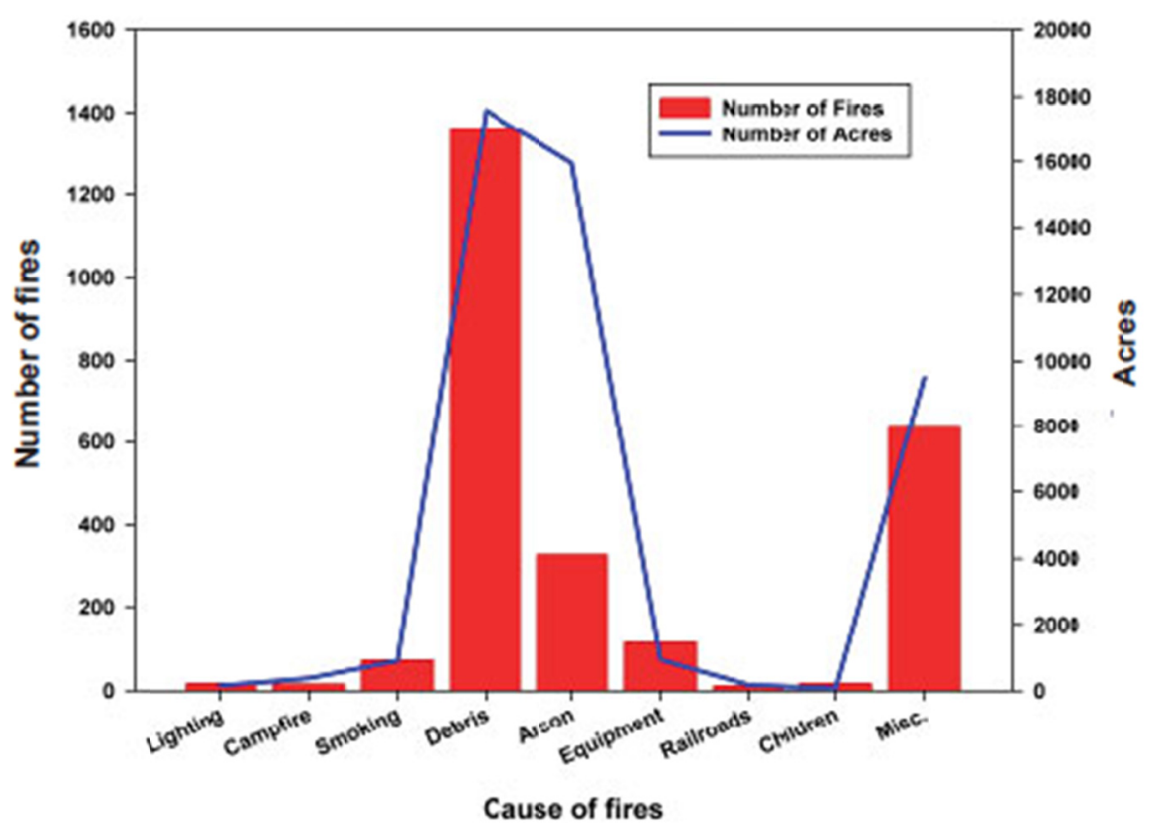

Figure 2. Wildfires and total acreage burned per year by cause in Missouri (1999-2008)

Source: Missouri Department of Conservation (MDC), 2008

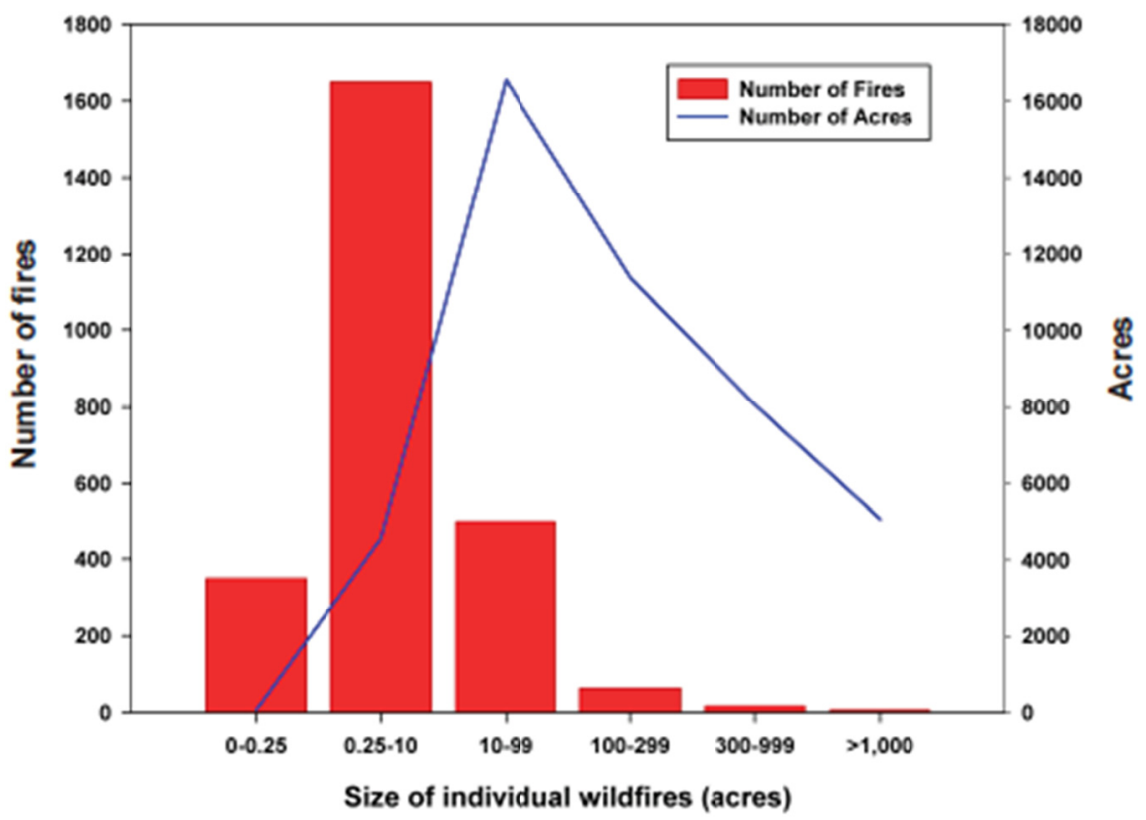

Figure 3. Wildfires per year by size in Missouri (1999-2008)

Source: Missouri Department of Conservation, 2008

\section{Wildfire Policy in the United States}

According to Steelman and Burke (2007) observed that the wildfire suppression policy is the first policy wildfire policy that was established in 1905. This policy was in operation for five decades, the policy failed to include ways to mitigate highly inflammable organic materials that were systematically over accumulated over time. The consequences of this over accumulation is that wildfires intensity became extremely high and this has accelerated the damaging potential of wildfires in American wildland. (USDA Forest Service, 2000; USDA Forest Service and 
DOI, 2000; GAO, 1999a, 1999b; National Commission in Wildfire Disasters, 1994).

Fire suppression involves aggressive firefighting. Aggressive firefighting alone cannot solve the wildfire problem (USDA Forest Service and DOI, 2000). The general believe is that firefighting has never proved to be an effective strategy for fuel-load reduction. This strategy has gained acceptance as a major approach for mitigating wildfire hazards. There are practical challenges with fuel reduction, this is the reason why mechanical fuel removal and prescribed burn are alternatives for fuel reduction. Apart from air pollution problem caused by prescribed burning, it has been discovered that there are problems arising from damage to ecosystem and human community (Busenberg, 2004). Effective fire-mitigation approach requires a lot of manpower and equipment over a period of time (Davis, 2006).

In addition to this, there is issues of transboundary policy regarding wildfire. This is because wildfires do not recognize geographical and political boundaries. Arising from this, there is need for close collaborations among various stake holders and individuals whose activities are impacted by wildfires (Busenberg, 2001; Davis, 2001, 2006; WGA, USDA, and DOI, 2001). This is what made Busenberg, (2004) to conclude that the present institution arrangement has not reduced wildfire but has created more ecological problems, prevention of wildfire has therefore remained complex, expensive, and risky.

\section{Recent Wildfire Policy Changes}

In recent time, the over emphasis on wildfire suppression policy alone has been found to be inefficient. Steelman and Burke (2007) observed that in the fall of 2000, a recommendation aimed at mitigating the adverse effects of wildfires on settlements and the environment as well as guaranteeing enough resources for future firefighting was submitted to President William J. Clinton. This recommendation and the attendant congressional appropriations led to the formulation of policy framework which today is referred to as the National Fire Plan (NFP). This $\$ 10$ billion and 10-year effort plan aimed at restoring forest ecosystems and human settlements. (Steelman and Burke, 2007).

In 2001, Congress in collaboration with Western Governors' Association (WGA) developed an organized national 10-year comprehensive approach for carrying out National Fire Plan (NFP). The NFP and the WGA 10-year comprehensive strategy identified some major objectives for mitigating the risk of wildfire and establishing collaboration at all governmental levels. These are to:

- Enhance fire prevention and suppression,

- Lessen hazardous fuels,

- Rebuild fire adapted ecosystems, and

- Encourage community assistance (WGA, 2001).

These efforts represent the first major attempt at shifting focus from wildfire suppression toward long term policies of protecting the natural environment and health of human settlement.

Steelman and Burke, (2007) argued that in 2002, the Healthy Forests Initiatives (HFI) was introduced by President George W. Bush. This initiative involves series of reforms aimed at improving the administrative bottlenecks, legislative actions, and procedural delays in implementing fuels reduction projects in the United States on up to 20 million acres of federal land.

The central focus of the HFRA is the Community Wildfire Protection Plan (CWPP). The idea is that for any community to have access to funding from the HFRA, the community should possess a CWPP. These CWPP arrangement is to bring together relevant stakeholders to develop a blueprint for tackling dangerous fuels in the Wildland Urban Interface (WUI). The intension of the CWPP according to Newman (2004) is to give local people disturbed by wildfire a sense of belonging in government mitigation management plans, and to give communities a sense of participation in wildfire risk management

\section{Challenges in the Implementation of Wildfire Policy in the United States}

There are funding challenges in the implementing of wildfire fuel reduction policy. Increase in funding for hazardous fuel reduction has failed to be proportionate with the amount proposed by Congress in the HFRA. Majority of the National Fire Plan (NFP) funding in each state in the United States since 2001/2002 were allocated to firefighting purposes and hazardous fuels treatments (Steelman et al., 2004). Only a smaller percentage were allotted to ecosystem restoration and community support.

Also, collaborative frameworks which is the central focus for executing the NFP and the 10-year comprehensive strategy, is not being utilized steadily at the local, state and national levels (WGA, 2004). Furthermore, 
collaborations at the state and regional level are not inclusive enough especially at national level as it does not provide significant involvement of non-federated collaborators (Daly, 2004; WGA, 2004; Gregory, 2005; Delaco, 2006). It has also been reported by Jensen (2006) that ground plan from CWPPs, which are meant to reorder wildfire alleviation approaches at different levels of government are not really implemented.

The major challenges confronting wildfire policy implementation in the United States can be summarized as lack of economic support and technical resources, non-appreciation of stakeholders achievements, inexperienced of agency employees, and unwillingness to innovation in the forest service (Daly 2004; Gregory, 2005; Delaco, 2006). There is also the legal challenge in expediting hazardous fuels treatments. The current approach still favors fire suppression and hazardous fuels reduction, and this creates partial remedy to the wildfire mitigation question. There is need to give the required institutional and financial attention they require.

\section{Critical Factors for Forest Fire Risk Reduction and Management in Missouri}

The first sector to consider is the social and demographic characteristics of the forest landowners in Missouri. This is very critical to wildfire risk mitigation. The aged population, income and low education are factors that enhance wildfire risk. Most of Missouri's forest are privately owned (see figures $4 \& 5$ ). About one-third of the private forest landowners are absentee owners because they do not live near their forest land, this increases forest fire incidence, only $32 \%$ of them have college degrees, and $34 \%$ are older than 65 years. These social and demographic characteristics of forest landowners have not encouraged wildfire risk mitigation efforts and management.

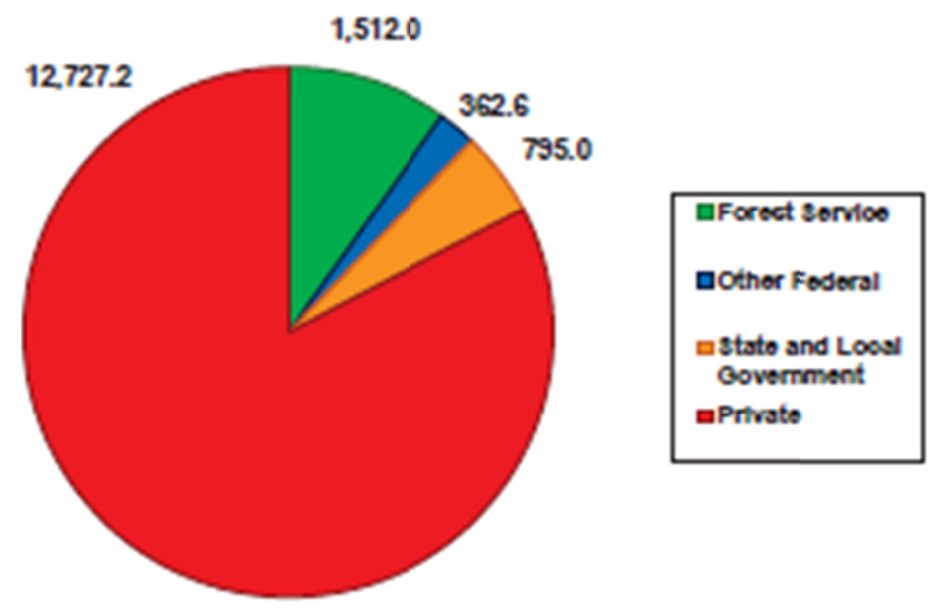

Figure 4. Missouri forest land ownership, by major ownership group, in thousands of acres

Source: Butler, 2008 


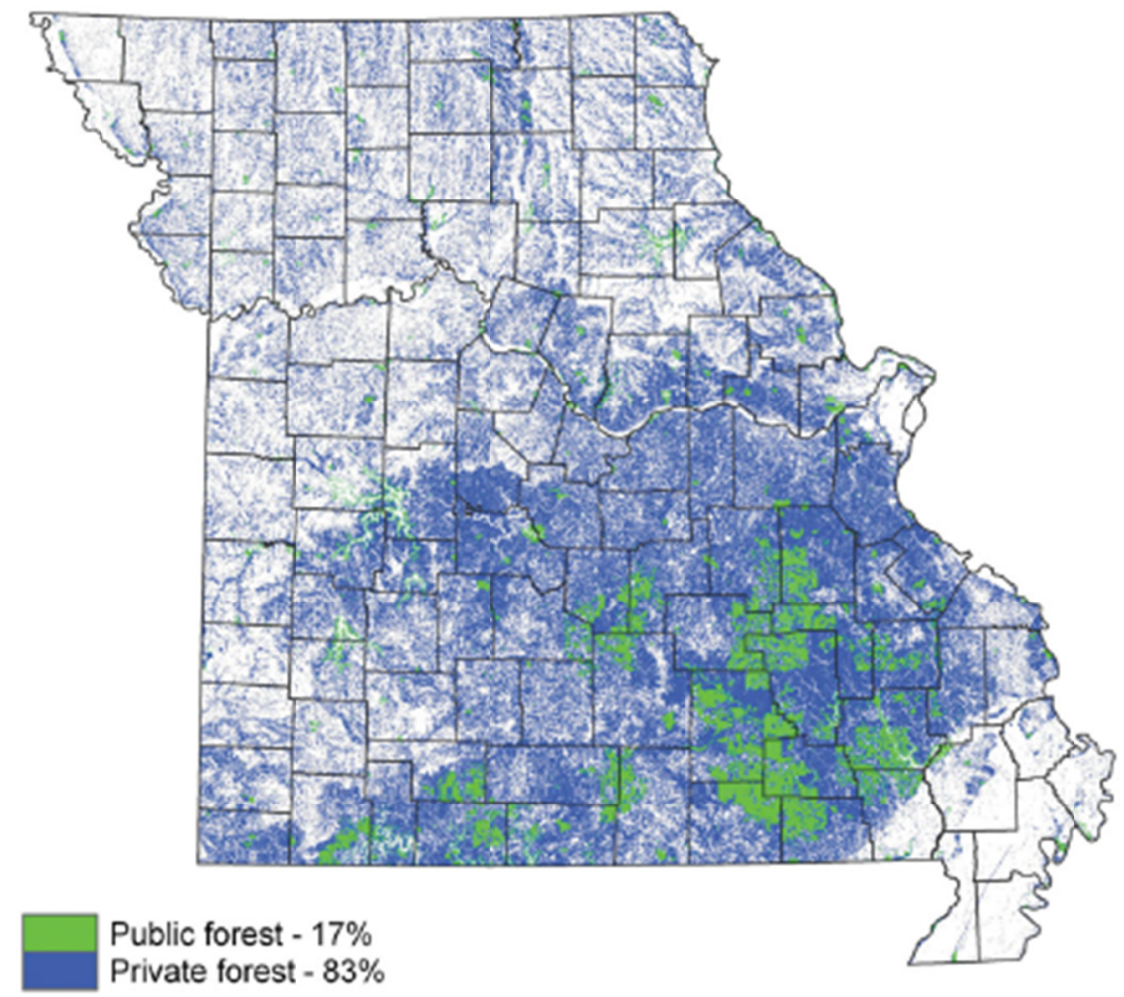

Figure 5. Forest land in Missouri by major owner group

Source: Map by Dacia Meneguzzo, U.S. Forest Service, Northern Research Station 2008

Source: Missouri Department of Conservation, 2008

Secondly, land use change in Missouri is another critical factor in wildfire risk reduction/management. The way land is from one generation of landowners to another have implications for forest fire occurrence and management.

Thirdly, recent changes in climate particularly precipitation exacerbates the severity of wildfire change. Missouri located in the hinterland has been observed has a region that will suffer from extreme drought condition. This will have implication for increase wildfire occurrence as the climatic condition becomes warmer (Intergovernmental Panel on Climate Change (IPCC) 2001).

In addition, the development of human settlements at the Wildland-Urban Interface (WUI) have led to the increase of wildfire occurrence in Missouri. This has made people and property at risk and created additional challenges to firefighters. Finally, the bureaucracy involved in implementing and complying with environmental regulations have been recognized as a major constraint to the ability of firefighters in mitigating the risk of wildfire to communities in Missouri (Steelman and Burke, 2006).

In conclusion, it has been observed that at present, Missouri does not have any state wildfire policy in place to tackle the menace of forest fire unlike states of California and Arizona. Such a wildfire policy when put in place should consider or take into cognizance the peculiarities of social and demographic characteristics of forest landowners in Missouri, Land Use Change, issues associated with Wildland Urban Interface (WUI) Climate Change, and Law prohibiting arson. These in addition to fuel load reduction as well as implementing Community Wildfire Protection Plan (CWPP). These in our view are challenges to be resolved in formulating an effective wildfire risk preparedness, prevention, reduction, mitigation and response strategies for Missouri.

\section{References}

Busenberg, G. (2004). Wildfire Management in the United States: The Evolution of a Policy failure. Review of Policy Research, 21(2), 145-156. https://doi.org/10.1111/j.1541-1338.2004.00066.x

Butler, B. J. (2008). Family Forest Owners in the United States, 2006. Gen. Tech. Rep. NRS-27, Newton Square, P.A.: U.S. Department of Agricultural Forest Service, Northern Research Station, 728. https://doi.org/10.2737/NRS-GTR-27 
Daly, C. (2004). Hearing before the subcommittee on forestry, conservation and Rural Revitalization of the Committee on Agriculture, Nutrition, and Forestry. Hearing on the implementation of the Healthy Forests Restoration Act. United States Senate $108^{\text {th }}$ Congress, $2^{\text {nd }}$ session.

Davis, C. (2004). The Healthy Forests Initiative: Unhealthy Policy choices in forest and fire management. Environ. Law, 34(4), 1209-1245.

Davis, C. (2006) Western Wildfires: A Policy Change Perspective. Review of Policy Research, 23(1), 115-127. https://doi.org/10.1111/j.1541-1338.2006.00188.x

Delaco, R. (2006). Hearing before the subcommittee on Public Lands and Forests concerning the Healthy Forests Restoration Act Implementation. United States Senate, $10^{\text {th }}$ Congress, July 19, 2006.

Gregory, L. (2005). Representative of the Wilderness Society testimony before the United States House of Representatives Committee on Resources subcommittee on Forests and Forest Health. USFS and BLM accomplishments on Healthy Forests Restoration Act, February 17, 2005.

Jensen, J. (2006). Hearing before the sub-committee on Public Lands and Forests concerning the Healthy Forests Restoration Act implementation. United States Senate, $109^{\text {th }}$ Congress, July 19, 2006.

Moser, W. K., Hansen, M. H., Butler, B. J., \& Treiman, T. B. (2009). Missouri's forest resources, 2008. Res. Note. NRS-40. Newtown Square, PA: U.S. Department of Agriculture, Forest Service, Northern Research Station. 4 p. https://doi.org/10.2737/NRS-RN-40

National Commission on Wildfire Disasters. (1994). Report of the National Commission on Wildfire Disasters. Washington, DC: American Forests.

Piva, R, J., \& Treiman, T. B. (2015). Forests of Missouri, 2014. Resource Update FS-40. Newtown Square, PA: U.S. Department of Agriculture, Forest Service, Northern Research Station. 4 p. https://doi.org/10.2737/FS-RU-40

Steelman, T. A., \& Burke, C. A. (2007). Is Wildfire Policy in the United States Sustainable? Journal of Forestry, 67-72. https://doi.org/10.2139/ssrn.1931057

US Department of Agriculture Forest Service and US Department of the Interior. (2000). Managing the impact wildfires on communities. Retrieved from http://www.fireplan.gov

US Department of Agriculture Forest Service. (2000). Protecting people and sustaining resources in fire-adapted ecosystem: A cohesive strategy. Retrieved from http://www.fs.fed.us/publication

US General Accounting Office. (1999a). Western National Forests: A cohesive strategy is needed to address catastrophic Wildfire threats. Washington, DC: US General Accounting Office.

US General Accounting Office. (1999b). Western National Forests: Nearby Communities are increasingly threatened by catastrophic wildfires. Washington, DC: General Accounting Office.

US General Accounting Office. (2000). Fire Management: Lessons learned from the Cerro Grande (Los Alamos) fire and actions needed to reduce fore risks. Washington DC: US General Accounting Office.

Western Governors' Association, US Department of Agriculture and US Department of the Interior. (2001). A collaborative approach for reducing wildland fire risks to communities: 10-year comprehensive strategy. Denver, CO: Western Governors' Association.

Western Governors' Association. (2004). Report to the Western Governors'on the implementation of the 10-year comprehensive strategy. Retrieved from www.wesgov.org/nga/initiatives/fire/temp-report.pdf

\section{Copyrights}

Copyright for this article is retained by the author(s), with first publication rights granted to the journal.

This is an open-access article distributed under the terms and conditions of the Creative Commons Attribution license (http://creativecommons.org/licenses/by/4.0/). 